\title{
Inteligencias Múltiples y Rendimiento Académico Área de Matemáticas en Estudiantes de Primer Grado en la Institución Educativa Ugel 04 Comas, Lima, 2018
}

\section{Multiple Intelligences And Academic Performance In The Area Of mathematics In First Grade Students At The Ugel 04 Comas Educational Institution, Lima, 2018}

\author{
Zaida América Claudio Salas Abelardo Rodolfo Campana Concha
}

\section{RESUMEN}

\begin{abstract}
Objetivo: Identificar la relación entre las inteligencias múltiples y el rendimiento académico en el Área de Matemáticas en estudiantes de Primer Grado en la Institución Educativa UGEL 04 Comas, Lima, 2018. Materiales y Método: Es un estudio de tipo correlacional que incluyó un cuestionario y test de conocimientos para sus variables 1 y 2, respectivamente, aplicados a una muestra de 68 estudiantes, y procesados estadíticamente con el programa SPSS. Resultados: La hipótesis general identificó una correlación buena de Rho $=.782$ entre las dos variables, dando cuenta que las inteligencias múltiples aplicadas mayoritariamente casi siempre consiguen que su rendimiento alcance el logro previsto en el área de matemáticas. Las estadísticas también confirmaron la relación entre la inteligencia linguística, matemática, espacial, fisica cinestésica, musical, interpersonal e intrapersonal ; y el rendimiento académico en el area de matemática.. Conclusión: La frecuencia en la que se realizan actividades para desarrollar este tipo de inteligencias resultan insuficientes para que los estudiantes alcancen las máximas calificaciones.
\end{abstract}

Palabras clave: Inteligencias múltiples, rendimiento académico, linguística, matemática, espacial, fisica cinestésica, musical, interpersonal, intrapersonal

\section{ABSTRACT}

Objective: To identify the relationship between multiple intelligences and academic performance in the Area of Mathematics in First Grade students at the Educational Institution UGEL 04 Comas, Lima, 2018. Materials and Method: It is a correlational study that included a questionnaire and knowledge test for its variables 1 and 2, respectively, applied to a sample of 68 students, and statistically processed with the SPSS program. Results: The general hypothesis identified a good correlation of Rho $=.782$ between the two variables, taking into account that the multiple intelligences applied mostly almost always achieve that their performance reaches the expected achievement in the area of mathematics. Statistics also confirmed the relationship between linguistic, mathematical, spatial, physical kinesthetic, musical, interpersonal and intrapersonal intelligence; and academic performance in the area of mathematics. Conclusion: The frequencies in which activities are carried out to develop this type of intelligence are insufficient for students to achieve the highest marks.

Keywords: Multiple intelligences, academic performance, linguistics, mathematics, spatial, kinesthetic physics, musical, interpersonal, intrapersonal.

\section{INTRODUCCIÓN}

Según la Evaluación Censal de Estudiantes realizado por el Ministerio de Educación (MINEDU, 2018a) el 55.0\% de los estudiantes de segundo grado alcanzado el nivel en inicio en el curso de matemática, es decir llegan a este grado académico con dificultades para resolver las actividades que se desarrollan en clases, esto puede deberse a muchos factores uno de estos, la metodología de enseñanza en los centros educativos.

Un error que comenten los docentes es suponer que todos los estudiantes tienen las mismas capacidades y habilidades, olvidando las inteligencias múltiples de Gardner (2006) quien reitera que una siempre sobresale sobre la otra. Suarez, Maiz y Meza (2010) refieren:

"Todas las personas tienen la capacidad de desarrollar las inteligencias a un nivel relativamente alto. Lo importante es tener la motivación y la instrucción adecuada" (p.87).

Si bien no todos tenemos las mismas inteligencias, se pude mejorar el rendimiento académico en matemáticas, si es que se enseña a partir del interés de los estudiantes, por ejemplo si el grupo tiene ese gusto musical se puede incluirla en la clase mientras resuelve un problema, para motivarlo. La idea es adaptar el espacio de estudio, despertando su interés por aprender desde sus propias inteligencias.

Sin embargo, Jáuregui (2016) señala que aún es un reto incluirlas claramente en la realidad educativa nacional, sabiendo que para el beneficio docente existen elementos tecnológicos que pueden facilitar nuestro trabajo, señalando que:

"La teoría de las inteligencias múltiple de Howard Gardner, constituye uno de los grandes aportes para la educación actual, sobre el tema de la inteligencia, las inteligencias múltiples, proporcionando una herramienta de apoyo en beneficio de los educandos, particularmente, dentro del proceso de enseñanza aprendizaje corresponde a los educadores y al estado, entonces responder a la altura de este nuevo escenario" (p.87).

Definitivamente éste es un problema que es urgente resolver desde el inicio de la etapa escolar, para mejorar el rendimiento académico en matemática, que incluso ha tenido de un efecto internacional debido a que apenas alcanza el nivel 1, de los 6 existentes, de la prueba PISA con 400 puntos (MINEDU, 2018b). 
Como antecedentes, nos apoyamos de en los estudios de Matos (2012) quien alertó que los estudiantes de dicha población en baja medida aplican las inteligencias lingüística y matemática, es decir los problemas matemáticos y la comprensión lectora son las dificultades que mayormente se presenta en la educación básica.

Además, Gómez (2012) en su tesis explicó que las bajas calificaciones en matemática se debe a la poca tecnología involucrada en clases además de que no se aplican "estrategias pedagógicas modernas en la institución, poco poder adquisitivo de los padres de familia, bajos niveles de formación académicos de los padres de familia" (p.42).

Por tanto, el objetivo de este estudio fue determinar la relación entre las inteligencias múltiples y el rendimiento académico en matemáticas en estudiantes de primer grado.

\section{MATERIAL Y MÉTODOS}

Es una investigación cuantitativa de diseño correlacional, que considera una población de 68 estudiantes, el cual también representa nuestra muestra. Se aplicó la técnica de la encuesta, y el cuestionario y test de conocimientos como instrumentos. Se aplicó la fórmula de Spearman mediante el programa computacional SPSS.

\section{RESULTADOS}

Tabla 1. Frecuencias inteligencias múltiples

\begin{tabular}{|c|c|c|c|c|}
\hline & & $\begin{array}{l}\text { Frecu } \\
\text { encia }\end{array}$ & $\begin{array}{l}\text { Porce } \\
\text { ntaje }\end{array}$ & $\begin{array}{l}\text { Porcentaje } \\
\text { acumulado }\end{array}$ \\
\hline \multirow{4}{*}{ Validos } & Algunas & 24 & 35,3 & 35,3 \\
\hline & veces & 37 & 54,4 & 89,7 \\
\hline & $\begin{array}{l}\text { casi siempre } \\
\text { siempre }\end{array}$ & 7 & 10,3 & 100,0 \\
\hline & Total & 68 & 100,0 & \\
\hline
\end{tabular}

Fuente: Zaida Claudio (2018)

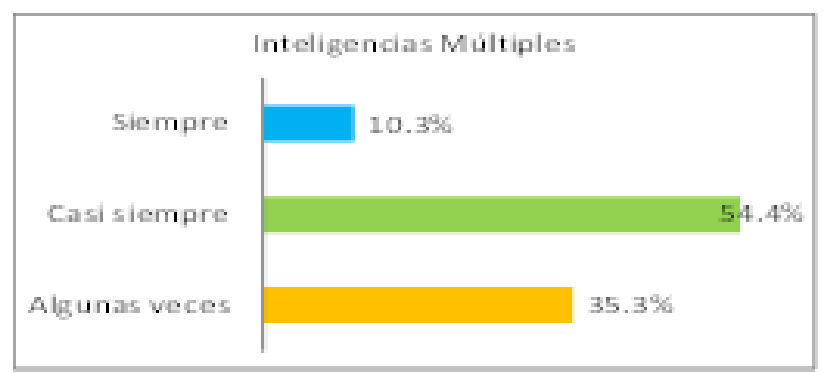

Figura 1. Porcentajes inteligencias múltiples

El $54,4 \%$ de los estudiantes indica que casi siempre los docentes realizan actividades que refuerzan sus inteligencias múltiples, el 35,3\% algunas veces y el 10,3\% como siempre, evidenciando una satisfacción positiva aunque no en un nivel máximo.
Tabla 2. Frecuencias del rendimiento académico en el área de matemática.

\begin{tabular}{lllll}
\hline & & $\begin{array}{l}\text { Frecuen } \\
\text { cia }\end{array}$ & $\begin{array}{l}\text { Porce } \\
\text { ntaje }\end{array}$ & $\begin{array}{l}\text { Porcentaje } \\
\text { acumulado }\end{array}$ \\
\hline Validos & Inicio & 1 & 1,5 & 1,5 \\
& $\begin{array}{l}\text { Proceso } \\
\text { Logro }\end{array}$ & 20 & 29,4 & 30,9 \\
& $\begin{array}{l}\text { Previsto } \\
\text { Logro }\end{array}$ & 11 & 162 & 100,0 \\
Destacado & & & \\
\cline { 2 - 5 } & Total & 68 & 100,0 & \\
\hline
\end{tabular}

Fuente: Zaida Claudio (2018)

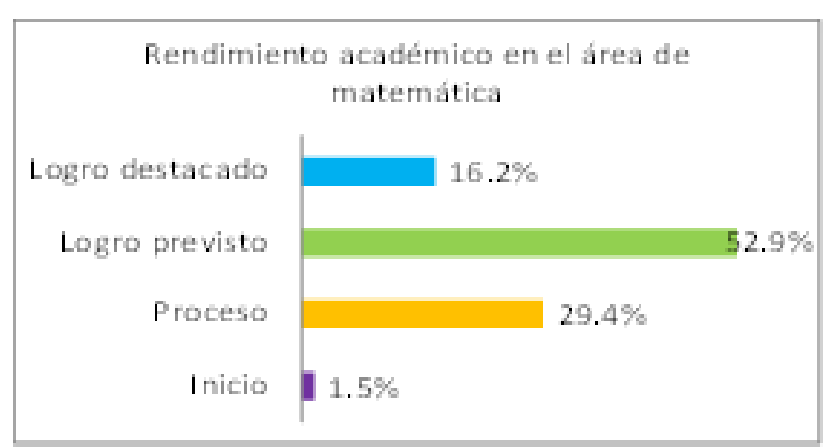

Figura 2. Porcentajes rendimiento académico en el área de matemática

El 52,9\% de los estudiantes alcanzó el logro previsto en el área de matemática, el $29,4 \%$ en proceso, el $16,2 \%$ en el logro destacado y el $1,5 \%$ en inicio, es decir, son buenas calificaciones, sin embargo no son las máximas.

\section{PRUEBA DE HIPÓTESIS GENERAL}

Ha. Las inteligencias múltiples se relacionan al rendimiento académico Área de Matemáticas en estudiantes.

Ho. Las inteligencias múltiples no se relacionan al rendimiento académico Área de Matemáticas en estudiantes.

Tabla 3.Correlación de la hipótesis general

\begin{tabular}{lllr}
\hline & Correlaciones & \multicolumn{2}{l}{$\begin{array}{l}\text { Rendimiento academico en } \\
\text { el aerea matematica }\end{array}$} \\
\hline $\begin{array}{lll}\text { Rho de } \\
\text { Spearman }\end{array}$ & $\begin{array}{l}\text { Inteligencias } \\
\text { multiples }\end{array}$ & $\begin{array}{l}\text { Coeficiente de } \\
\text { correlacion } \\
\text { Sig.(bilateral) }\end{array}$ &, 782 \\
\cline { 3 - 4 } & $\mathrm{N}$ & 600 \\
\end{tabular}

Fuente: Zaida Claudio (2018)

Con margen de error de $5 \%$, se halló una correlación buena de Rho $=.782$ y el $p=0,000$, con ello la aceptación de la hipótesis alterna.

\section{Contrastación hipótesis específica 1}

Ha. La inteligencia lingüística se relaciona al rendimiento académico Área de Matemáticas en estudiantes de primer grado. 
Ho. La inteligencia lingüística no se relaciona al rendimiento académico Área de Matemáticas en estudiantes de primer grado.

Tabla 4. Primera contrastación específica

\begin{tabular}{|c|c|c|c|}
\hline & Correlaciones & & linguistica \\
\hline \multirow[t]{3}{*}{$\begin{array}{l}\text { Rho de } \\
\text { Spearman }\end{array}$} & $\begin{array}{l}\text { Rendimiento } \\
\text { academico }\end{array}$ & $\begin{array}{l}\text { Coeficiente de } \\
\text { correlacion }\end{array}$ &, $527^{* \star}$ \\
\hline & Area de & Sig.(bilateral) &, 000 \\
\hline & & $\mathrm{N}$ & 68 \\
\hline
\end{tabular}

Fuente: Zaida Claudio (2018).

Se estableció una correlación moderada de Rho $=.527$ y el $p=$ 0,000 , con ello la aceptación de la hipótesis alterna.

\section{Contrastación hipótesis específica 2}

Ha. La inteligencia matemática se relaciona al rendimiento académico Área de Matemáticas en estudiantes de primer grado.

Ho. La inteligencia matemática no se relaciona al rendimiento académico Área de Matemáticas en estudiantes de primer grado.

Tabla 5.Segunda contrastación específica

\begin{tabular}{lllr}
\hline \multicolumn{3}{c}{ Correlaciones } & Matemática \\
\hline $\begin{array}{l}\text { Rho de } \\
\text { Spearman }\end{array}$ & $\begin{array}{l}\text { Aprendizaje del } \\
\text { área de } \\
\text { matematicas }\end{array}$ & $\begin{array}{l}\text { Coeficiente de } \\
\text { correlación } \\
\text { Sig.(bilateral) }\end{array}$ &, $600^{* *}$ \\
\cline { 3 - 4 } & $\mathrm{N}$ &, 000 \\
\hline
\end{tabular}

Fuente: Zaida Claudio (2018)

La estadística que se aplicó es de un margen de error de $5 \%$. Se determinó una correlación buena de Rho $=.600$ y el $p=$ 0,000 , con ello la aceptación de la hipótesis alterna.

\section{Contrastación hipótesis específica 3}

Ha. La inteligencia espacial se relaciona al rendimiento académico Área de Matemáticas en estudiantes de primer grado.

Ho. La inteligencia espacial no se relaciona al rendimiento académico Área de Matemáticas en estudiantes de primer grado.

Tabla 6. Tercera contrastación específica

\begin{tabular}{lllr}
\hline \multicolumn{3}{c}{ Correlaciones } & Espacial \\
\hline $\begin{array}{lllr}\text { Rho de } \\
\text { Spearman }\end{array}$ & $\begin{array}{l}\text { Aprendizaje del } \\
\text { área de } \\
\text { matematicas }\end{array}$ & $\begin{array}{l}\text { Coeficiente de } \\
\text { correlación } \\
\text { Sig.(bilateral) }\end{array}$ &, $463^{\text {** }}$ \\
\cline { 3 - 4 } & $\mathrm{N}$ &, 000 \\
\hline
\end{tabular}

Fuente: Zaida Claudio (2018)
Con margen de error de $5 \%$. Se identificó una correlación moderada de Rho $=.463$ y el $p=0,000$, con ello la aceptación de la hipótesis alterna.

\section{Contrastación hipótesis específica 4}

Ha. La inteligencia física cinestésica se relaciona al rendimiento académico Área de Matemáticas en estudiantes de primer grado.

Ho. La inteligencia física cinestésica no se relaciona al rendimiento académico Área de Matemáticas en estudiantes de primer grado.

Tabla 7. Cuarta contrastación específica

\begin{tabular}{lllr}
\hline & Correlaciones & \multicolumn{2}{c}{ Física cinestésica } \\
\hline $\begin{array}{l}\text { Rho de } \\
\text { Spearman }\end{array}$ & $\begin{array}{l}\text { Aprendizaje del } \\
\text { área de } \\
\text { matematicas }\end{array}$ & $\begin{array}{l}\text { Coeficiente de } \\
\text { correlación } \\
\text { Sig.(bilateral) }\end{array}$ &, $381^{* *}$ \\
\cline { 3 - 4 } & $\mathrm{N}$ &, 001 \\
\hline
\end{tabular}

Fuente: Zaida Claudio (2018)

Con margen de error de $5 \%$. Se halló una correlación baja de Rho $=.381$ y el $p=0,000$, con ello la aceptación de la hipótesis alterna.

\section{Contrastación hipótesis específica 5}

Ha. La inteligencia musical cinestésica se relaciona al rendimiento académico Área de Matemáticas en estudiantes de primer grado.

Ho. La inteligencia musical cinestésica no se relaciona al rendimiento académico Área de Matemáticas en estudiantes de primer grado.

Tabla 8. Quinta contrastación específica

\begin{tabular}{lllr}
\hline \multicolumn{3}{c}{ Correlaciones } & Musical \\
\hline $\begin{array}{l}\text { Rho de } \\
\text { Spearman }\end{array}$ & $\begin{array}{l}\text { Aprendizaje del } \\
\text { área de } \\
\text { matemáticas }\end{array}$ & $\begin{array}{l}\text { Coeficiente de } \\
\text { correlación } \\
\text { Sig.(bilateral) }\end{array}$ &, $657^{* *}$ \\
\cline { 3 - 4 } & $\mathrm{N}$ &, 000 \\
\hline
\end{tabular}

Fuente: Zaida Claudio (2018)

La estadística que se aplicó es de un margen de error de $5 \%$. Se identificó una correlación buena de Rho $=.657$ y el $p=$ 0,000 , aceptando la Ha.

\section{Contrastación hipótesis específica 6}

Ha. La inteligencia interpersonal se relaciona al rendimiento académico Área de Matemáticas en estudiantes de primer grado.

Ho. La inteligencia interpersonal no se relaciona al rendimiento académico Área de Matemáticas en estudiantes de primer grado. 
Tabla 9. Sexta contrastación específica

\begin{tabular}{|c|c|c|c|}
\hline & Correlaciones & & Interpersonal \\
\hline \multirow[t]{3}{*}{$\begin{array}{l}\text { Rho de } \\
\text { Spearman }\end{array}$} & $\begin{array}{l}\text { Aprendizaje del } \\
\text { área de }\end{array}$ & $\begin{array}{l}\text { Coeficiente de } \\
\text { correlación }\end{array}$ &, $657^{* *}$ \\
\hline & matemáticas & Sig.(bilateral) & ,000 \\
\hline & & $\mathrm{N}$ & 68 \\
\hline
\end{tabular}

N68Fuente: Zaida Claudio (2018).

Con margen de error de $5 \%$. Con el cual se identificó una correlación buena de Rho $=.657$ y el $p=0,000$, con ello la aceptación de la hipótesis alterna.

\section{Contrastación hipótesis específica 7.}

$\mathrm{Ha}$. La inteligencia intrapersonal se relaciona al rendimiento académico Área de Matemáticas en estudiantes de primer grado.

Ho. La inteligencia intrapersonal no se relaciona al rendimiento académico Área de Matemáticas en estudiantes de primer grado.

Tabla 10. Séptima contrastación específica

\begin{tabular}{|c|c|c|c|}
\hline & Correlaciones & & Intrapersonal \\
\hline \multirow[t]{3}{*}{$\begin{array}{l}\text { Rho de } \\
\text { Spearman }\end{array}$} & $\begin{array}{l}\text { Aprendizaje del } \\
\text { área de }\end{array}$ & $\begin{array}{l}\text { Coeficiente de } \\
\text { correlación }\end{array}$ &, $647^{* *}$ \\
\hline & matemáticas & Sig.(bilateral) & ,000 \\
\hline & & $\mathrm{N}$ & 68 \\
\hline
\end{tabular}

Fuente: Zaida Claudio (2018).

Con margen de error de $5 \%$, se identificó una correlación buena de Rho $=.647$ y el $p=0,000$, con ello la aceptación de la hipótesis alterna.

\section{DISCUSIÓN DE LOS RESULTADOS}

En la hipótesis general existe una relación buena de Rho = .782, que a opinión del $54,4 \%$ de la muestra, las inteligencias múltiples son reforzadas casi siempre, sin embargo el 35,3\% considera que sucede algunas veces; con respecto al rendimiento académico del área de matemática, el 52,9\% alcanza el logro previsto, seguido del $29,4 \%$ en un nivel en proceso. Esto explica que la frecuencia establecida en la que los docentes están realizando actividades en beneficio de las inteligencias múltiples tiene una implicancia relacional en las calificaciones de los estudiantes en el curso de matemáticas, que precisamente no son destacadas.

En la hipótesis específica 1, la mayoría de la muestra $(41,2 \%)$ consideró oportuno señalar que casi siempre se desarrollan actividades para reforzar la inteligencia lingüística, por el contrario el $30,8 \%$ opina que es siempre. En tanto que, el rendimiento académico del área de matemática, el 52.9\% alcanza el logro previsto, seguido del $29,4 \%$ en un nivel en proceso, del cual se identificó una moderada de Rho $=, 527$. Con ello se alerta que las actividades que involucran aspectos como las palabras, el relato de historias, debates y persuasión están relacionadas a las calificaciones del curso de matemática.

La HE2 encontró una relación buena de Rho $=, 600$, cuyo resultado se debe a que la muestra, en su mayoría, representado por un $54,4 \%$ casi siempre desarrollan su inteligencia matemática, seguido del $38,2 \%$ quienes consideran que sucede algunas veces; con respecto al rendimiento académico del área de matemática, el 52,9\% alcanza el logro previsto, seguido del $29,4 \%$ en un nivel en proceso. En otras palabras, los cálculos, los razonamientos y las deducciones numéricas están relacionados a las calificaciones alcanzadas en el curso de matemática.

La HE3 halló una correlación moderada de Rho $=.463$, en donde la muestra $(66,1 \%)$ señala que casi siempre refuerzan su inteligencia espacial, en tanto que, otra porcentaje indica que algunas veces $(22,1 \%)$; con respecto al rendimiento académico del área de matemática, el 52,9\% alcanza el logro previsto, seguido del $29,4 \%$ en un nivel en proceso. Es decir, que los aspectos que involucran la percepción y creación de imágenes (color, línea, forma, figura y espacio) están relacionados a las calificaciones en matemática de los estudiantes de primaria.

La HE4 estableció una relación baja de Rho $=, 381$, debido a que la mayoría de los estudiantes opinan que casi siempre $(57,4 \%)$ se les brindan actividades que refuerzan su inteligencia física cinestésica, seguido de un porcentaje que considera que solo sucede algunas veces $(36.8 \%)$; por otro lado, en el rendimiento académico del área de matemática se destacan calificaciones que representan el logro previsto $(52,9 \%)$, seguido del nivel en proceso (29.4\%). Esta estadística explica que, elementos como la coordinación, el equilibrio, la destreza, la fuerza u otros aspectos que involucre el cuerpo para expresar ideas están relacionados a los alcances en las notas en el área de matemáticas.

En la HE5 se encontró una correlación buena de Rho = ,657, puesto que las actividades que refuerzan la inteligencia musical se desarrolla algunas veces $(47,1 \%)$, sin embargo otro porcentaje $(42,6 \%)$ considera que es casi siempre; por otro lado, en el rendimiento académico del área de matemática se destacan calificaciones que representan el logro previsto $(52,9 \%)$, seguido del nivel en proceso $(29,4 \%)$. Por ello, se evidencia que las actividades para expresar y percibir diferentes representaciones musicales están relacionadas a las calificaciones de este curso en el nivel primario.

La HE6 demostró la existencia de una correlación buena de Rho $=.657$, debido a la estadística aplicada, que explica que las actividades en beneficio de la inteligencia interpersonal se desarrollan casi siempre (50.0\%), seguido del $36.8 \%$ que opina de algunas veces; mientras que en el rendimiento académico del área de matemática se destacan calificaciones que representan el logro previsto (52,9\%), seguido del nivel en proceso $(29,4 \%)$. Evidenciando que la acción de percibir y comprender actitudes y estados de ánimos de otras personas tiene relación en las notas alcanzadas en el curso.

La HE7 estimó que existe una relación buena de Rho = ,647,además que se encontró que la mayoría $(51,5 \%)$ considera que se realiza casi siempre se realizan actividades en beneficio de la inteligencia interpersonal, seguido del 35,3\% 
que opina de que sucede algunas veces; mientras que, lo que los niveles académicos en el área de matemática, se destacan por el logro previsto y en proceso, con porcentajes del 52,9\% y $29,4 \%$, respectivamente. Alertando que el reconocimiento de su propio estado anímico está vinculado a sus calificaciones en el curso de matemática.

Estos resultados pueden ser contrastados con los de Cifuentes (2017) quien comprobó que las inteligencias múltiples, en especial la emocional, incide de forma favorable en el rendimiento matemático, luego de aplicar un programa de intervención psicopedagógica, lo que les ha permitido comprender, manejar los problemas matemáticos. En cambio, este estudio considera que se necesita del reforzamiento de las distintas inteligencias (lingüística, matemática, espacial, física cinestésica, musical, Interpersonal e intrapersonal) ya que mientras más se ejercite estas habilidades las calificaciones alcanzarán el logro destacado.

Otra investigación a destacar es la de Benites y Benites (2015) quienes luego de una encuesta a los docentes de su población de estudio identificó que el entorno familiar es el principal inconveniente para el aprendizaje de las matemáticas, ya que los estudiante encuentran ahí elementos distractores, como los aparatos electrónicos, que los hace descuidar sus estudios. Estos resultados en parte son avalados por nuestros resultados, ya que si no se refuerza las inteligencias múltiples sus capacidades serán limitadas, por más tiempo que el docente le dedique a reforzarlas en clase, también es necesario el compromiso de los padres de familia.

\section{CONCLUSIONES}

1.Las actividades para desarrollar este tipo de inteligencias resultan insuficientes para que los estudiantes alcancen las máximas calificaciones.

2.Las actividades que involucran aspectos como las palabras, el relato de historias, debates y persuasión resultan insuficientes para que los estudiantes de primaria consigan la escala máxima de calificaciones.

3.Las actividades en referencia a los cálculos, los razonamientos y las deducciones numéricas son insuficientes para un mejor promedio académico en el aula de primer grado.

4.Las actividades que involucran la percepción y creación de imágenes (color, línea, forma, figura y espacio) son insuficientes para que los estudiantes de primaria tengan las máximas calificaciones en el curso de matemáticas.

5.Se concluye que las actividades en referencia a la coordinación, el equilibrio, la destreza, la fuerza u otros aspectos son insuficientes para un mejor promedio académico en el aula de primer grado.

6.Las actividades para expresar y percibir diferentes representaciones musicales resultan insuficientes para que los estudiantes de primaria consigan la escala máxima de calificaciones.

7.Las actividades que permiten percibir y comprender actitudes y estados de ánimos de otras personas son insuficientes para que los estudiantes de primaria tengan las máximas calificaciones en el curso de matemáticas.

8.Las actividades que involucran el reconocimiento de su propio estado anímico resultan insuficientes para que los estudiantes de primaria consigan la escala máxima de calificaciones.

\section{AGRADECIMIENTO}

A mi familia por su constante apoyo.

\section{REFERENCIAS BIBLIOGRÁFICAS}

Benites, J. y Benites, V. (2015). Factores que dificultan el aprendizaje de matemáticas en las estudiantes del quinto grado de educación secundaria de la I.E San José de Tarbes-Piura, 2015 [Tesis Magisterial, Universidad de Piura].

Cifuentes, M. (2017). La influencia de la inteligencia emocional en el rendimiento matemático de alumnos de educación secundaria. Aplicación de un programa de intervención psicopedagógica de educación emocional [Tesis doctoral, Universidad Camilo José $\left.\begin{array}{lllll}C & e & l & a\end{array}\right]$ https://repositorio.ucjc.edu/bitstream/handle/20.500. 12020/286/Tesis\%20Doctoral M\%C2\%AA\%20Elisa bet $\% 20$ Cifuentes.pdf? sequence $=1$ \&isAllowed $=y$

Gómez, F. (2012). Elementos problemáticos en el proceso de enseñanza de las matemáticas en estudiantes de la Institución Educativa Pedro Vicente Abadía [Tesis de Magíster, Universidad Nacional de Colombia]. http://www.bdigital.unal.edu.co/7052/1/7810033.201 2.pdf

Jáuregui, E. (2016). La teoría de las inteligencias múltiples ¿Práctica docente en la educación en el Perú? Educación, 22.

Matos, M. (2012). Inteligencias múltiples en estudiantes de tercer grado de secundaria de una institución educativa de Ventanilla - Callao [Tesis de Magoster, Universidad de San Ignacio de Loyola].

Ministerio de Educación (2018a). Resultados 2018. Evaluaciones de logros de aprendizaje.https://issuu.com/medu m c/docs/presentacion-webece2018 bcc8e4fc1a7ebf

Ministerio de Educación (2018b). Evaluación PISA 2018. https://es.calameo.com/read/006286625977c1ced4d $\underline{6 c}$ ? view $=$ slide $\&$ page $=28$

Suarez, J., Maiz, F. y Meza, M. (2010). Inteligencias múltiples: una innovación pedagógica para potenciar el proceso enseñanza aprendizaje. Investigación y Postgrado, $25 \quad(1), \quad 81-94$. https://dialnet.unirioja.es/descarga/articulo/5330850. pdf 